\title{
Analysis of Model Tests of Rainfall-Induced Soil Deposit Landslide
}

\author{
JianJun Gan $\mathbb{D}^{1,2}$ and Y. X. Zhang ${ }^{2}$ \\ ${ }^{1}$ JiangXi Engineering Research Center of Water Engineering Safety and Resources Efficient Utilization, \\ Nanchang Institute of Technology, Nanchang 330099, China \\ ${ }^{2}$ School of Computing Engineering and Mathematics, Western Sydney University, Sydney, NSW 2751, Australia \\ Correspondence should be addressed to JianJun Gan; 2014994522@nit.edu.cn
}

Received 25 August 2019; Revised 23 February 2020; Accepted 24 June 2020; Published 22 July 2020

Academic Editor: Salvatore Grasso

Copyright (c) 2020 JianJun Gan and Y. X. Zhang. This is an open access article distributed under the Creative Commons Attribution License, which permits unrestricted use, distribution, and reproduction in any medium, provided the original work is properly cited.

\begin{abstract}
A large number of deposit landslides are induced by rainfall, and those with different weak layers may be subject to catastrophic failure. This research investigates the rainfall infiltration effect on the stability of deposit landslides with a weak layer at different slope angles. Four rainfall physical model tests were conducted with fixed double penetration artificial rainfall technique and dynamic sensor technologies by using the rainfall test methods as modified in the paper. Deformation and mechanics parameters, as well as water content parameters in the key position in the deposit landslide, were monitored by means of various displacement monitoring sensors, dynamic soil pressure sensors, pore water pressure (PWP) monitoring sensors, and water content sensors. The results show that, under the same rainfall conditions, the rule of displacement and mechanical changes of deposit slope with different angles are similar, that the displacement, soil pressure, and PWP are characterized by two stages of rising and falling, and that the displacement of deposit slope with weak layer remains creep after rainfall. In addition, the displacement at the rear edge of the slope with a small angle is larger than that at the front of the steep slope, but the displacement in the front of the slope is opposite. Furthermore, the slope with a smaller angle is prone to form a tensile crack in the back of the slope, and its deformation and failure have the characteristics of a progressive and thrust-type landslide. While the failure in front of a steep slope (slope angle more than $60^{\circ}$ ) occurred first, the slope failure was characterized by sudden and retrogressive modes. The mathematical analysis of the model is also conducted which shows that deformation and failure can be divided into three stages, i.e., creep inoculation, accumulation uplift, and speed-up sliding. The test results can provide a reference for the investigation, design, and assessment of similar deposit slopes.
\end{abstract}

\section{Introduction}

Rainfall infiltration has a great influence on the stability of deposit slopes, especially the deposit slope with weak layers, which is prone to landslide [1]. These rainfallinduced deposit landslides with weak layers pose a lot of threats to the masses in mountainous areas due to their strong concealment and complex formation mechanism [2-6]. In recent years, in view of the frequent occurrence situation of deposit landslides, lab and field investigation, as well as the numerical analysis, was conducted to study the mechanical and deformation mechanism of landslides. Chen and Tang [7] and Forte et al. [8] used the geometric similarity method of approximate geometric similarity and conducted physical indoor rainfall tests to study the start-up of the loose landslides. Crosta and Frattin [9] used three distributed hydrological models to analyze the slippage of shallow overburden deposit slope under the heavy rainfall and studied the distribution rule of hundreds of deposit landslides in the Alps. Li et al. [10] used the borehole inclinometer to monitor the deformation of the landslide sliding zone of the accumulation slope and analyzed the deformation stage of the deposit landslide. A rainfall test was carried out to study the instability of the soil and rock mixed deposit slope by means of the rainfall test, and the changes of infiltration rate and pore water pressure were analyzed $[11,12]$. 
A physical model was used to conduct rainfall simulation tests with different slopes for accumulation landslide and a warning model of rainfall-type landslide based on rainfall duration and rainfall was proposed [13]. Gao et al. [14] used GeoStudio software to simulate multifield characteristics of accumulation landslide under different rainfall conditions. Wang et al. [15] derived a landslide stability coefficient expression using the GA model. Tian et al. [16] conducted experimental analysis on the displacement field deformation of loose deposit slope by using centrifugal rainfall simulation equipment, and Jeong et al. [17] and Sun et al. [18] analyzed the landslide of soil deep foundation with numerical analysis and physical modeling test.

These experimental or numerical studies at the lab or field have mostly focused on the relationship between landslide failure and rainfall of deposit landslide. The effect on deposit landslide with a weak layer under different slope angles induced by rainfall has seldom been considered. On the one hand, due to the complexity of the geological structure of accumulation slope with a weak layer, the displacement or mechanical parameters may be random by indoor simulation or numerical method. On the other hand, rainfall infiltration has both horizontal and vertical infiltration on the deposit slope with different slope angles, while the traditional landslide hydrogeological cycle takes the change of the same seepage field into account. Nevertheless, there are few studies on the two-way seepage problems such as soil-water contact fracture zone, dissolution zone, and vertical crack under complex engineering-geological conditions.

In this paper, the Nanheng Bridge deposit landslide in Longnan county, Jiangxi province, China, which was induced by rainfall on 20 March 2016 is investigated. This landslide is mainly characterized by a three-layer structure: the sliding bed composed of carboniferous limestone and sandstone, the slide zones composed of silty clay, and the sliding body mainly composed of gravel deposit. Another typical feature is that there are three transverse landslide cracks in the back of the slope. In order to measure the mechanical and deformation parameters of the landslide with special geological structure, three strata of the artificial rainfall simulation test model and four angle slope models are developed, and several monitors are set in the different positions of the slide zone and main body. The characteristics and deformation failure mechanism of the deposit landslide with the weak layer on different angles under artificial rainfall are analyzed. Numerical analysis of rainfall infiltration is also conducted in this paper using the improved Green-Ampt model, and the effect of nonuniform changes of the wetting front along vertical cracks and inclined weak layers has been considered.

\section{The Prototype Landslide}

The prototype landslide is located $1.0 \mathrm{~km}$ downstream of Nanheng town. The main body of the landslide is composed of clastic rock, fill soil, silty clay, and gravel soil with an average particle size of $0.5 \mathrm{~m}$ (accounting for 50-60\%), and the underlying bedrock is limestone and sandstone with a dip angle of $28-35^{\circ}$. The main structural traces in this deposit are SW-NE about $560 \mathrm{~m}$ wide and $616 \mathrm{~m}$ long, with a relative height difference of $224 \mathrm{~m}$, and the total volume was estimated to be $1.2 \times 10^{6} \mathrm{~m}^{3}$. Rainfall in this area mainly occurs in March and June accounting for $53.5 \%$ of the annual precipitation. Some of the rainfall is turned into the surface water downflow to the Wo river at the foot of the landslide, and others infiltrate into the ground through surface cracks and overburden interstices, forming a weak and muddy sliding surface that is not conducive to slope stability. The geological section of the deposits landslide is shown in Figure 1.

Geophysical prospecting, drilling, trenching, and well exploration have been taken into survey and analysis of this landslide, and it was found that the landslide occurred mainly above the bed weak layer with a dip angle about $30^{\circ}$. The thickness of the main body is $2 \mathrm{~m}$ to $45 \mathrm{~m}$, and the leading edge is mainly composed of filling the soil with a maximum thickness of $14 \mathrm{~m}$. The sliding zone is developed in the weak layer at the junction of highly weathered limestone and accumulation body. The weak layer is about 0.8-3.0 $\mathrm{m}$ thick with a buried depth of 10-32 $\mathrm{m}$ with a water content of $35-41 \%$. Rainfall is the causal factor of this landslide, and mudding of the slide zone soil is the main failure reason of the Nanheng landslide, which is a kind of planar landslide in the deep layer (see Figure 1).

\section{Test Model}

3.1. Model Setting. The model setting was conducted to understand the geological features in the area and the mechanism of the landslide deposits with a weak layer. The field data and experimental data including different dip angles are used, and the main slide section which has formed three tension cracks [19] is chosen in this study. The simulation range is $28 \mathrm{~m}$ in depth and $150 \mathrm{~m}$ in length from the main scarp to the top. Finally, the model with a depth of $30 \mathrm{~m}$ and a length of $146.4 \mathrm{~m}$ was selected. Therefore, the landslide model is $513 \mathrm{~mm}$ in width, $1,466 \mathrm{~mm}$ in length, and $53 \mathrm{~mm}$ high base of the Law of Similarity Theory.

The theoretical basis of the simulation experiment is the similarity principle, that is, the model is required to be similar to the entity (prototype), and the model can reflect the situation of the entity. The similarity theory is the main basis of the simulation experiment. According to the mechanical mechanisms, the similarity theory mainly includes mechanical similarity, material similarity, initial condition similarity, and boundary condition similarity [18].

The model is similar to the research object, which needs to satisfy certain relations in terms of geometric conditions, force conditions, and friction coefficient. In summary, the similarity principle can be expressed as follows: if two systems are similar (model and prototype), their geometric characteristics and each physical quantity must be proportional to each other. It can be defined as follows.

Similarity coefficient of geometric conditions:

$$
C_{L}=\frac{L_{P}}{L_{M}} .
$$




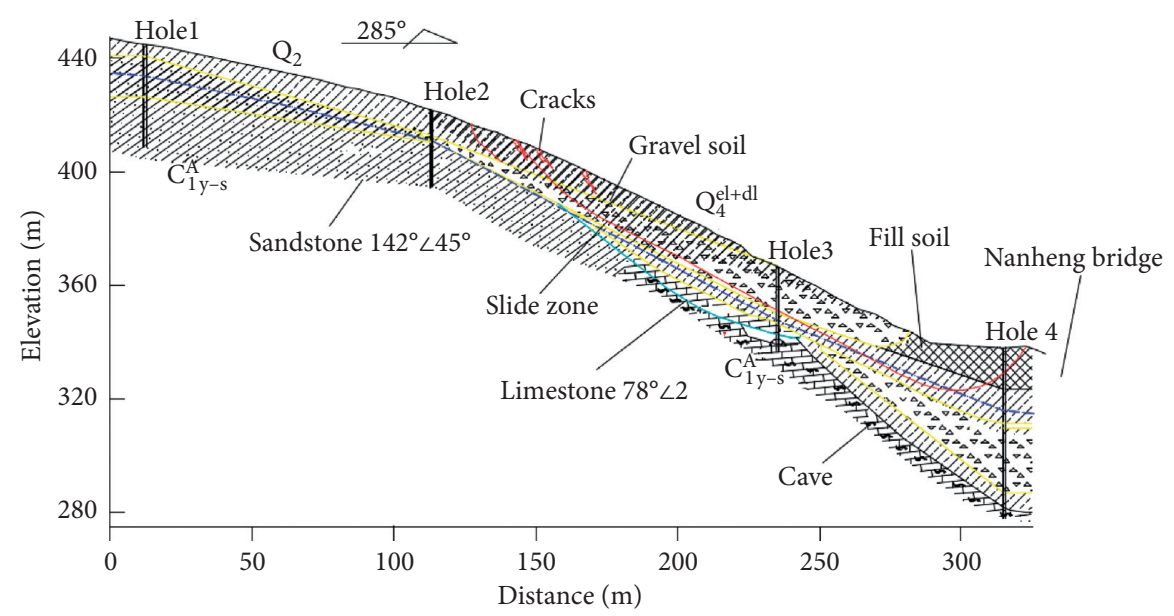

Figure 1: Geological section of deposit landslide in Nanheng.

Similarity coefficient of force conditions:

$$
C_{V}=\frac{V_{P}}{V_{M}}, \text { or } C_{e}=\frac{e_{P}}{e_{M}},
$$

where $C$ is the similarity coefficient; $L$ is the geometric size; $V$ is the density of materials; $e$ is the stress; and the subscripts $P$ and $M$ represent the prototype and model, respectively [20-22].

It is placed in a steel frame reinforced glass boxes with $2,300 \mathrm{~mm}$ in length, $1,200 \mathrm{~mm}$ in width, and $1,000 \mathrm{~mm}$ in height. This glass box is fully enclosed except the top and a $60 \mathrm{~mm}$ diameter drainage pipe with a switch was installed at the front of the landslide. Meanwhile, in order to study the deformation and failure of the landslide with different dip angles, two model boxes were made with each separated by a $70 \mathrm{~mm}$ thick plank, and four models were tested simultaneously. The schematic cross section and the test model of the artificial simulation of the test are shown in Figure 2 [23].

In order to observe the data, the model box is made transparent around, and a $10 \mathrm{~mm}$ by $10 \mathrm{~mm}$ grid is affixed in the direction of the profile. Test slope base of $371 \mathrm{~mm}$ in height, $880 \mathrm{~mm}$ in length, and $513 \mathrm{~mm}$ in width was built by 49 black bricks which are $230 \mathrm{~mm}$ long, $110 \mathrm{~mm}$ wide, and $53 \mathrm{~mm}$ thick. To simulate the infiltration of rainfall into the weak interlayer of the main body along the transverse cracks of the landslide, 10 filter pipes (Johnson pipes) with a diameter of $12 \mathrm{~mm}$ were inserted in the rear edge of the landslide, and a layer of plastic rain cloth with a thickness of $0.5 \mathrm{~mm}$ was laid on the blue brick to form the waterproof layer. A weak interlayer mainly composed of fine sand about $25 \mathrm{~mm}$ thick with a dip angle $26^{\circ}$ was built on the rain cloth, and the particle size of the sand is 20-40 mesh. $280 \mathrm{~mm}$ thick granite weathering soil was placed on top of a weak layer. The granite weathered soil was screened with a mesh of less than $50 \mathrm{~mm} \times 50 \mathrm{~mm}$ to remove impurities such as plant roots.

The artificial rainfall system is composed of a control console, a large function pump, a spraying system, a data monitoring, and an automatic collection system. The rainfall system is composed of four subrainfall zones (three downspout zones and one side spout zone), and each subrainfall subsystem could be operated independently. The total area of effective rainfall is $784 \mathrm{~m}^{2}$, and the total area of rainfall has 3 downcast areas and 1 side spray area. The effective rainfall height is $18 \mathrm{~m}$, and the rain chute system is set in the three downcast areas, which can well solve the ineffective rain before and after the rain in downcast areas. The continuous variation range of rain strength is $10-200 \mathrm{~mm} / \mathrm{h}$ in the downflow area. The side spray area is $30-300 \mathrm{~mm} / \mathrm{h}$, and various rainfall conditions of $10-500 \mathrm{~mm} / \mathrm{h}$ can be simulated by the under spray and side spray tissues. Rainfall uniformity is greater than 0.80 , and the storage capacity of the collector is more than 32,000 pieces. The rainfall sampling interval is 10-9,999 seconds.

3.2. Model Material and Similarity Ratio. According to the principles of the geometric similarity ratio, the similarity ratio of this experimental model is $1: 100$. Given that the mechanical mechanism of prototype landslide is a thrusttype landslide, we select 1:1 for the gravity similarity ratio. Other physical indexes between the prototype and the model can be derived according to the similarity theory and they are listed in Table 1.

Field investigation has shown that the water content of the shallow surface rock and soil of this landslide deposit was extremely low. Rainfall infiltration was along the tension cracks and soil pore into the weak layer. Deposit slope will experience skipping and damage along the shear plane if the sliding force of the potential shear plane (weak layer) exceeds the antiskipping force landslide [19, 24]. Therefore, the similarity ratio of the mechanical parameter in the weak layer is very important. As the main stratum lithology of the weak layer is the highly weathered limestone and residual slope overburden, the saturated infiltration of the sliding surface and geological analytical method were used in this test, which is based on lithology, particle diameter ratio, and water content. The slide zone soil of the prototype landslide is taken from the field exploration and sampling. The mixing ratio of the weak layer model is tailing sand: fly ash: talc: water $=73: 9: 11: 7$. The mixing ratio of the main body of the 


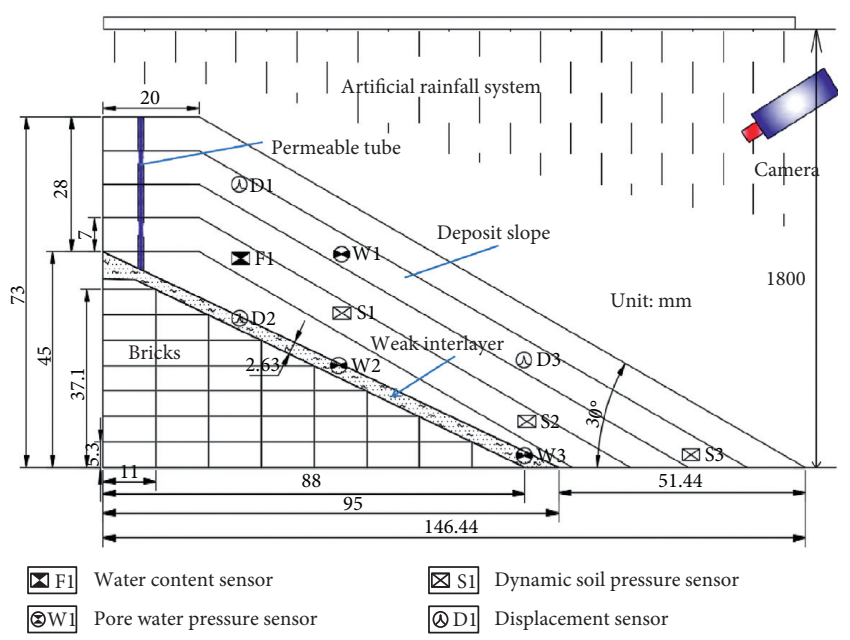

(a)

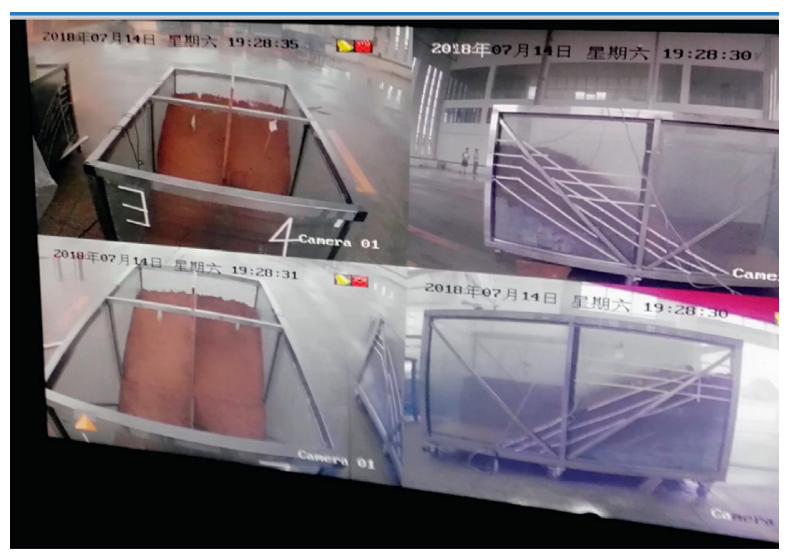

(b)

Figure 2: Design of artificial rainfall simulator for the test model. (a) Schematic cross section. (b) Photograph of the test model.

TABle 1: Physical parameter similarity ratio.

\begin{tabular}{lcc}
\hline Parameter & Definition & Similarity ratio \\
\hline Length & $C_{l}=L_{p} / L_{m}$ & 100 \\
Volume weight & $C_{\gamma}=\gamma_{p} / \gamma_{m}$ & 1 \\
Rainfall intensity & $C_{q}=q_{p} / q_{m}$ & 10 \\
Rainfall duration & $C_{t}=t_{p} / t_{p}$ & 10 \\
Cohesion & $C_{c}=C_{p} / C_{m}$ & 100 \\
Angle of friction & $C_{\varphi}=\varphi_{p} / \varphi_{m}$ & 1 \\
Displacement & $C_{\delta}=\delta_{p} / \delta_{m}$ & 100 \\
Shear stress & $C_{\tau}=\tau_{p} / \tau_{m}$ & 100 \\
Coefficient of permeability & $C_{k}=k_{p} / k_{m}$ & 10 \\
Modulus of compression & $C_{E s}=k_{E s} / k_{E s}$ & 100 \\
\hline
\end{tabular}

model slope is red granite weathering soil: fine sand: water $=83: 12: 5$. The main parameter similarity ratio of the rainfall model is shown in Table 2 .

In this work, we modified the rainfall test method proposed by Li et al. [10] by introducing a new artificial rainfall system with continuous rainfall, which can be carried out in four models simultaneously. The unit weight of the soil in the model slope was strictly controlled by weighing in advance, and the water content was controlled by calculating in advance and evenly spraying on the soil in the filling process with measuring cylinder and sprinkling kettle. Mechanical parameters such as cohesion, internal friction angle, permeability coefficient, and compression modulus were determined by a laboratory test. The prototype landslide had continuous rainfall of 24 hours from 20 O'clock on March 19, 2016, to 20 O'clock on March 20, 2016, with a total rainfall of $150 \mathrm{~mm}$. Meanwhile, the rainfall was mainly concentrated in the first 6 hours (the average rain strength was about $25 \mathrm{~mm} / \mathrm{h}$ ). According to the principle of similitude ratio, with the total rainfall as the control factor, rain intensity of $10 \mathrm{~mm} / \mathrm{h}$ was used for the first 3 hours, then $30 \mathrm{~mm} / \mathrm{h}$ for another 2 hours, and finally $60 \mathrm{~mm} / \mathrm{h}$ for the subsequent 1 hour. The automatic monitoring data lasted for 24 hours. To maintain the uniformity and accuracy of the rainfall, the rain was first filtered for 15-20 minutes before the formal model test. In this process, a rain clothe was used to cover the test model, until the rain was uniform and reached the designed rain strength. After this, we open the rain cloth and begin timing (Figure 3).

3.3. Monitoring Equipment. A new automatic monitoring system has been designed for the model test, mainly including pore water pressure (PWP), soil pressure, displacement monitoring, and automatic camera monitoring system. Three CYY2 PWP dynamic sensors, three CYY9 dynamic soil pressure sensors, three CYY-TR-WY integrated bidirectional soil displacement sensors, and one RS485 digital soil-water sensor were deployed at different locations of each model. Four high-definition cameras were placed around the four models (see Figure 3 for the artificial rainfall synthesis system (Table 3)).

All sensors are digitized through the integration of highfrequency amplifiers; then, the voltage signal is converted into stress or strain signal by a specially designed conversion software. Hikvision DS-2CD2T25XY-SW with 3 million pixels are specifically designed to monitoring the test day and night. The advantages of the monitoring system include a large range, small size effect, durable water repellency, and all the deformation and mechanic parameters during the rainfall process are generated from the execution recording of the real-time software (Figure 4).

3.4. Test Procedures. Four models of rainfall experiment were carried out at the same time, and the slope angles of these models were set at $30^{\circ}, 45^{\circ}, 60^{\circ}$, and $75^{\circ}$. The main experimental procedures include the following: (1) installation and fixation of the base of the model box and then model making; (2) sieving granite weathering soil, fine sand, and so on according to the similarity ratio, preparing similar materials of landslide deposit and soft layer, and strictly controlling related parameters such as water content and density; (3) layering related materials according to the 
TABLE 2: Main parameter similarity ratio of rainfall model.

\begin{tabular}{lccccccc}
\hline Material & Type & $\begin{array}{c}\text { Unit weight } \gamma \\
\left(\mathrm{kN} / \mathrm{m}^{3}\right)\end{array}$ & $\begin{array}{c}\text { Soil moisture } \\
\omega(\%)\end{array}$ & $\begin{array}{c}\text { Cohesion } c \\
(\mathrm{kPa})\end{array}$ & $\begin{array}{c}\text { Friction angle } \\
\Phi\left(^{\circ}\right)\end{array}$ & $\begin{array}{c}\text { Infiltration } \\
\text { coefficient } K(\mathrm{~cm} / \mathrm{s})\end{array}$ & $\begin{array}{c}\text { Modulus of } \\
\text { compressibility } E_{s}(\mathrm{MPa})\end{array}$ \\
\hline Residual & Prototype & 1.78 & 26.4 & 24.6 & 21.4 & $2.1 \times 10^{-5}$ & 5.40 \\
soil & Model & 1.80 & 26.5 & 0.25 & 21.3 & $2.0 \times 10^{-6}$ & 0.05 \\
\hline Weak & Prototype & 1.96 & 41.2 & 33.1 & 19.3 & $2.9 \times 10^{-6}$ & 5.85 \\
layer & Model & 1.95 & 40.5 & 0.34 & 19.5 & $3.0 \times 10^{-7}$ & 0.06 \\
\hline
\end{tabular}
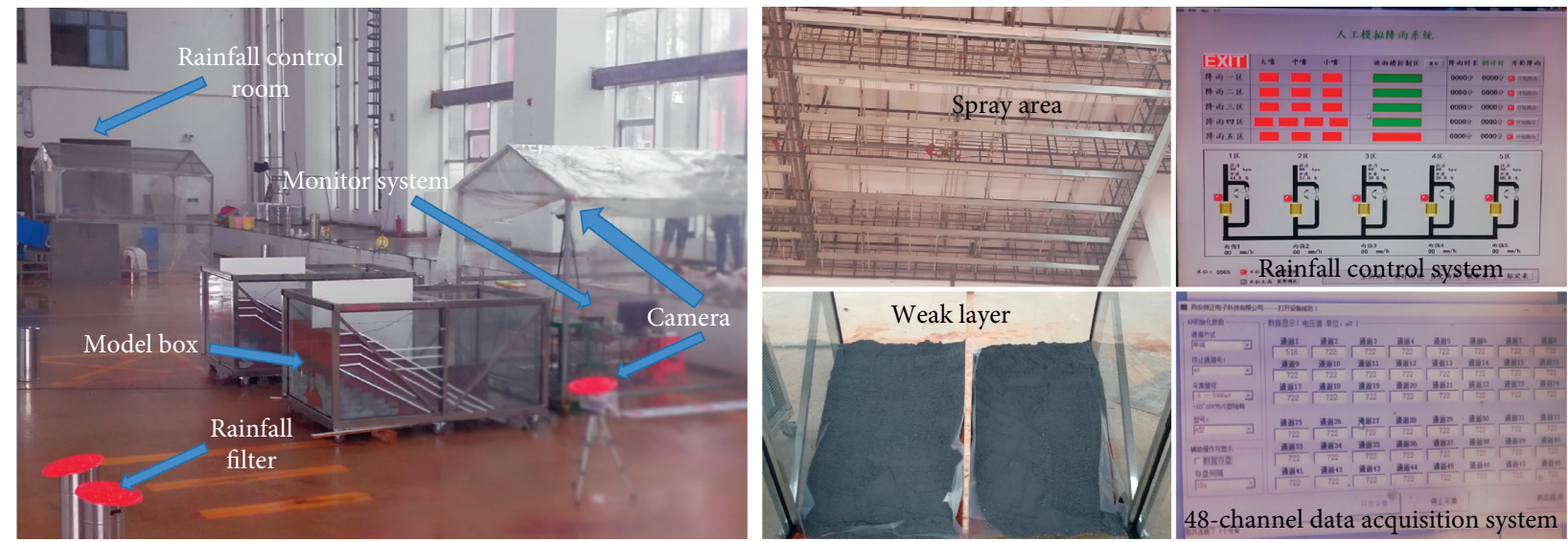

Figure 3: Artificial rainfall synthesis system.

TABLE 3: Monitoring equipment connected to the model test.

\begin{tabular}{|c|c|c|c|c|}
\hline Test purposes & Type & Spec. & Number & Output \\
\hline PWP & CYY2 & Precision: $\pm 0.5 \%$; range: $0 \sim 2 \mathrm{kPa}$ & 2 per model & $0 \sim 5 \mathrm{VDC}$ \\
\hline Soil pressure & CYY9 & Precision: $\pm 0.25 \%$; range: $0 \sim 50 \mathrm{kPa}$; & 2 per model & $0 \sim 5 \mathrm{VDC}$ \\
\hline Soil moisture & RS485 & Precision: $\pm 3 \%$; range: $0 \sim 100 \%$; & 1 per model & $0 \sim 5 \mathrm{VDC}$ \\
\hline Displacement & CYY-TR-WY & Precision: $\pm 0.5 \%$; range $0 \sim 500 \mathrm{~mm}$; & 2 per model & $0 \sim 5 \mathrm{VDC}$ \\
\hline Data acquisition and voltage stabilizer & CYY -58 & 100 channels & 1 & $0 \sim 24 \mathrm{VDC}$ \\
\hline Webcam & $\begin{array}{c}\text { DS-2CD2T25XY-SW } \\
\text { (Hikvision) }\end{array}$ & Image size: $1920 \times 1080$ & 1 per model & 220VDC \\
\hline
\end{tabular}

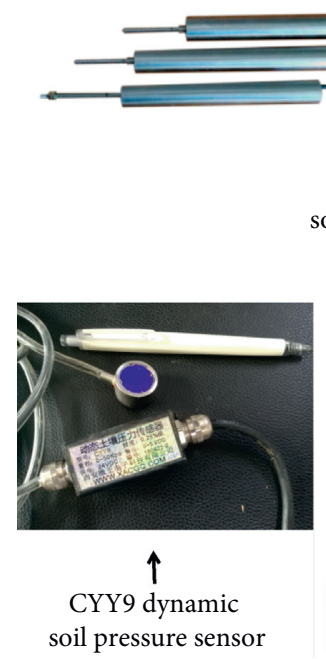

soil pressure sensor
CYY-TR-WY

soil displacement sensor

RS485

soil moisture

sensor

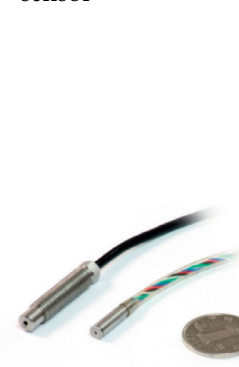

(a)

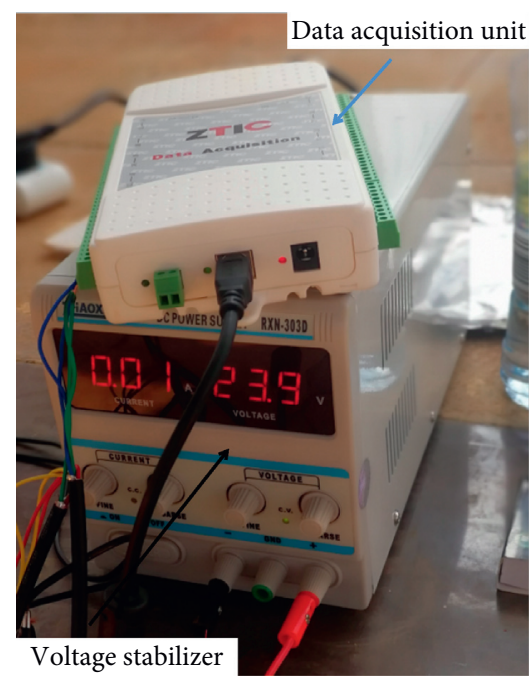

(b)

FIgure 4: Monitor of the test model. (a) Sensor. (b) CYY-58 data acquisition unit and voltage stabilizer. 
sequence of blue brick, rain cloth, weak layer, and landslide deposit, meanwhile installing various monitoring instruments in different depths according to the design; (4) laying the landslide deposit in four layers, with each layer of $7 \mathrm{~cm}$ in thickness, and the specifications marked on the side plate shall be used to control the stratification compaction; (5) after the commissioning of the various monitoring instruments, the rain test starts. When the rainfall is uniform, the formal test is conducted according to the predetermined rainfall conditions. If the slope is deformed and damaged, it must stop; and (6) monitoring the changes of water content, pore water pressure, soil pressure, and displacement in the process of rainfall, and continue monitoring until the full 24 hours after rainfall stops.

\section{Experiment Results and Analysis}

4.1. Characteristics of Slope Deformation and Failure of the Test Model with Different Slope Angles. The largest displacement of the back edge was observed in the $30^{\circ}$ slopes angle model followed by the $45^{\circ}$ slope angle model, the $60^{\circ}$ slope angle model, and the $75^{\circ}$ slope angle mode. Conversely, the largest displacement occurred in the front of the slope model with $75^{\circ}$ slope angle, followed by the $60^{\circ}$ slope angle model, the $45^{\circ}$ slope angle mode, and the $30^{\circ}$ slope angle model (Figure 5).

In Figure 6, the variation characteristic of the displacement at the back of the test models with a slope angle of $30^{\circ}, 45^{\circ}, 60^{\circ}$, and $75^{\circ}$ is plotted. Displacement of shallow of the deposit slope (D1 sensor location) was found to increase with the rainfall duration, but failure did not occur simultaneously in different slope angles. The largest displacement measure was $16.7 \mathrm{~mm}$ in the $30^{\circ}$ slope angle model, and the displacement measure of $45^{\circ}, 60^{\circ}$, and $75^{\circ}$ slope angle models was $14.5 \mathrm{~mm}, 8.0 \mathrm{~mm}$, and $7.3 \mathrm{~mm}$, respectively. In addition, in the process of rainfall, the largest displacement growth rate of the deposit model with a $30^{\circ}$ slope angle was $1.2 \mathrm{~mm} / \mathrm{h}$, which is 2.3 to 5.2 times greater than that at the same location with $60^{\circ}$ slope angle. The displacement growth rate of the model with a $45^{\circ}$ slope angle was about $0.6 \mathrm{~mm} / \mathrm{h}$. The displacement at $24 \mathrm{~h}$ is about 2.1-4.2 times of the deformation before rainfall.

Displacements in the weak layer of the test model (D2 sensor location) are compared with the measured data by the D2 sensor in Figure 6. As shown in the figure, the displacement grows from big to small in turn for slope angle $30^{\circ}$ to $75^{\circ}$ in the weak layers of these models. Combined with the displacement monitoring results in the rainfall duration, the displacement growth rate of the main body of the deposit slope (D1 sensor location) is 2-3.5 times that of the weak layer (D2 sensor location), while the maximum displacement of the shallow of the model is 1.8-3.2 times that of the weak layer. Moreover, it is shown that the displacement of the weak layer grows continuously in the rainfall stop stage, and the displacement at $24 \mathrm{~h}$ is $1.5-4.9 \mathrm{~mm}$, which is large than that at the $6 \mathrm{~h}$. The displacement of the weak layer of slope continues to creep after rainfall, which has a great influence on the stability of the slope, so it should be taken seriously.

The displacement of surface and front of these models with different slope angles is shown in Figure 7. The largest displacement growth rate is in the surface and front of the model with $75^{\circ}$ slope angle before rainfall, followed by the $60^{\circ}, 45^{\circ}$, and $30^{\circ}$ slope angles. The monitoring showed that the final displacement of the $75^{\circ}, 60^{\circ}, 45^{\circ}$, and $30^{\circ}$ slope angles after the rain was $10.6 \mathrm{~mm}, 7.7 \mathrm{~mm}, 7.1 \mathrm{~mm}$, and $7.5 \mathrm{~mm}$, respectively. This indicates that the steeper side slope of the accumulation body is more likely to form a shear outlet from the slope foot leading to traction landslide. On the contrary, if the slope is gentler, the same bedrock bedding slope is prone to cause a thrust-type landslide. In practice, modification of slope should be paid attention to the steep toe, while for the gentle slope, the waterproof of the transverse crack at the back part of the slope should be paid special attention to, and the drainage measures should be taken as far as possible to prevent the infiltration of rainwater.

4.2. Characteristics of the Mechanical Change of Test Model with Different Slope Angles. In order to illustrate the effect of different slopes on the mechanical mechanism of the deposit slope with weak layer, two CYY9 dynamic soil pressure sensors were set in $200 \mathrm{~mm}$ depth in the back part and middle part of the test model, and the other CYY9 dynamic soil pressure sensor was set in the $150 \mathrm{~mm}$ depth in the front of the test model. Figure 8 compares the soil pressure histories of the different part of the test model with a slope angle of $30^{\circ}, 45^{\circ}, 60^{\circ}$, and $75^{\circ}$. According to Figure 8(a), the soil pressure in the depth of the back part of the slope increases gradually with the rainfall. When the rainfall stopped, the dynamic soil pressure still increases to a certain extent, but after about $9 \mathrm{~h}$ of monitoring, the soil pressure reaches the highest and then gradually decreases. It can be seen from the curve characteristics of Figure 8(a) that the soil pressure changes through two stages, namely, steep first and then slow down. In addition, the soil pressure in the back of test model (S1 sensor location) was reduced followed by the increase of the slope angle, and the soil pressure order is $\mathrm{P}_{30^{\circ}}>\mathrm{P}_{45^{\circ}}>\mathrm{P}_{60^{\circ}}>\mathrm{P}_{75^{\circ}}$.

In the middle part of the test model (Figure $8(\mathrm{~b})$ ), the soil pressure change follows these rules also, and the soil pressure increases first and then slows down. Meanwhile, the maximum soil pressure is $2.32 \mathrm{kPa}$ in the $30^{\circ}$ slope which appears around $10 \mathrm{~h}$ and is an internal factor inducing landslide. In the front of the test model (Figure $8(\mathrm{c})$ ), the soil pressure increases rapidly from $0 \mathrm{~h}$ to $10 \mathrm{~h}$, indicating that the sum of soil mass and water weight of the front of the test model increases all the time. But 4 hours after the rainfall stops, the soil pressure decreases, and the largest reduction of soil pressure is $560 \mathrm{~Pa}$ in the $75^{\circ}$ slope, followed by a pressure reduction of $220 \mathrm{~Pa}$ in the $60^{\circ}$ slope, $120 \mathrm{~Pa}$ in the $45^{\circ}$ slope, and $110 \mathrm{~Pa}$ in the $30^{\circ}$ slope. This suggests that the front of the slope with a weak layer is prone to collapse and form a shear outlet at the toe of the test model.

The soil pressure changes in three stages of the slope as shown in Figure 8. The common characteristic of the three stages is that the soil pressure in the back part of the slope with the weak layer increases rapidly before rainfall, while the soil pressure decreases continuously after rain. The difference between them is that the slope of the bedding deposit slope with the same bedrock dip angle has different 


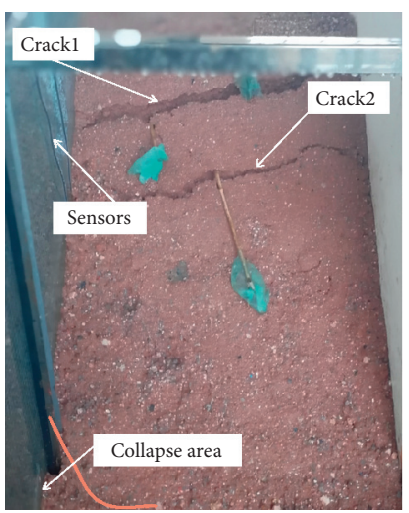

(a)

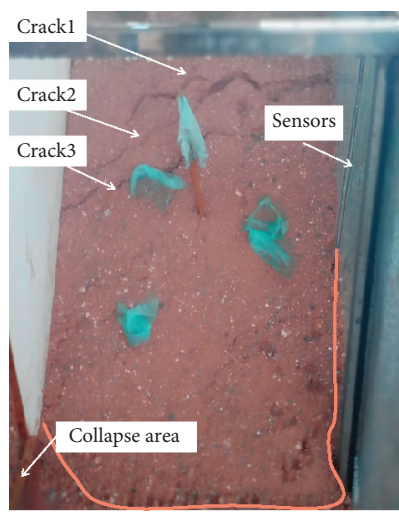

(b)

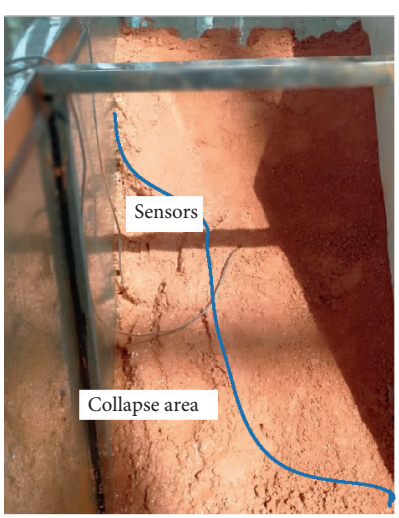

(c)

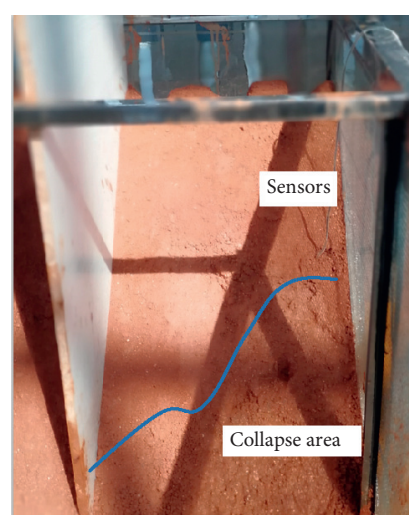

(d)

Figure 5: Photo of displacement after rainfall. Slope with (a) $30^{\circ}$ angle, (b) $45^{\circ}$ angle, (c) $60^{\circ}$ angle, and (d) $75^{\circ}$ angle.

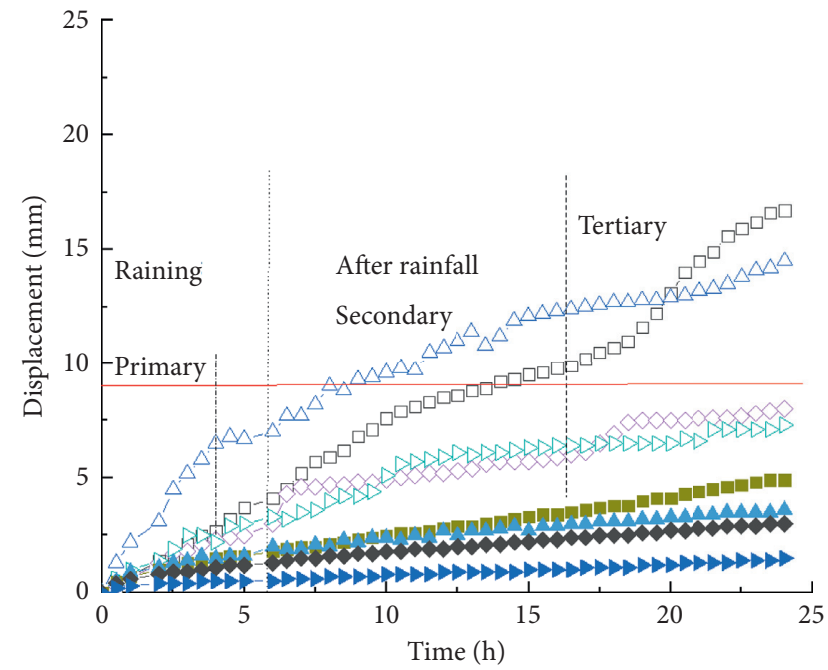

$-\square-\mathrm{D} 1$ monitor in a $30^{\circ}$ slope $-\square-\mathrm{D} 2$ monitor in a $30^{\circ}$ slope $-\triangle-$ D1 monitor in a $45^{\circ}$ slope $-\Delta-$ D2 monitor in a $45^{\circ}$ slope $\rightarrow-$ D1 monitor in a $60^{\circ}$ slope $\rightarrow-$ D2 monitor in a $60^{\circ}$ slope $\rightarrow-$ D1 monitor in a $75^{\circ}$ slope $\rightarrow-$ D2 monitor in a $75^{\circ}$ slope

FIgURE 6: Characteristics of the displacement in the back part of the models (D1 and D2 sensor location).

effects on the change of soil pressure at different positions [25]. During the rainfall process, the largest pressure growth rate is in the back part of the test model, followed by a pressure growth rate in the middle part of the slope and the soil pressure growth rate in the front of the test model. But in the descent stage after rainfall, the soil pressure of the test model decreases with time, and the rate is rather high at the initial stage and then slows down afterward. The soil pressure-time curves of the simulation show that descent rates in the back part are less than the descent rate in the middle part, and the fastest reduction rate of soil pressure occurs in the front of the test model with a $75^{\circ}$ angle.

\subsection{Characteristics of Pore Water Pressure of Test Model with} Different Slope Angles. Experimental observations have revealed that the PWP-time curve of the test model with different

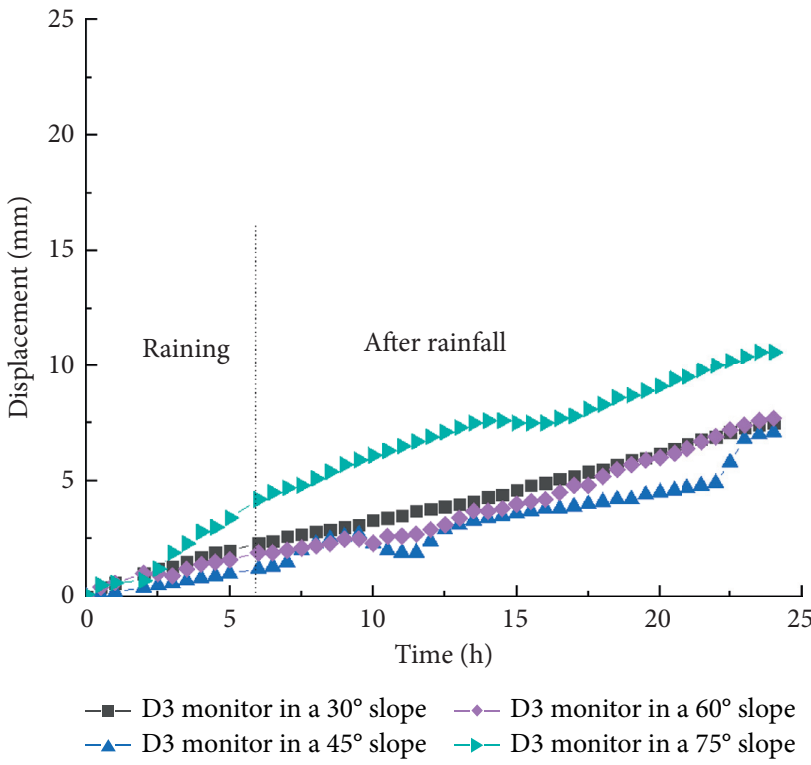

Figure 7: Displacement of shallow surface in front of the models (D3 sensor location).

slope angles is characterized by an increase with time and then a decrease after rainfall (see Figure 9). The PWP in the shallow back part of the test model increased rapidly from $-280 \mathrm{~Pa}$ to $370 \mathrm{~Pa}$ during the rainfall. When the rainfall stopped at $6 \mathrm{~h}$, the pore water pressure was rapidly permeated where the water moves downward, and the peak mostly occurred at ten hours since rainfall. The increments of PWP are similar between the four curves of these models before the peak point of each curve is reached. But after the peak point, the PWP in the back part of the slope (Figure 9(a)) dropped to 20-30 Pa. With its rapid increase in the process of soil pressure and rainfall, expansion and contraction of the crown cracks are formed. With the same rainfall conditions and duration, the maximum $\mathrm{PWP}$ in the back of the slope has an order of $P_{\mathrm{w} 75^{\circ}}>P_{\mathrm{w} 30^{\circ}}>P_{\mathrm{w} 45^{\circ}}>P_{\mathrm{w} 60^{\circ}}$.

In Figure 9(b), the PWP in the weak layer at the middle of test model (W2 sensor location) has a steep rise stage in the rainfall process, but the PWP does not stop to rise after 6 hours of the rainfall stop, and it still increases until 10 hours. 


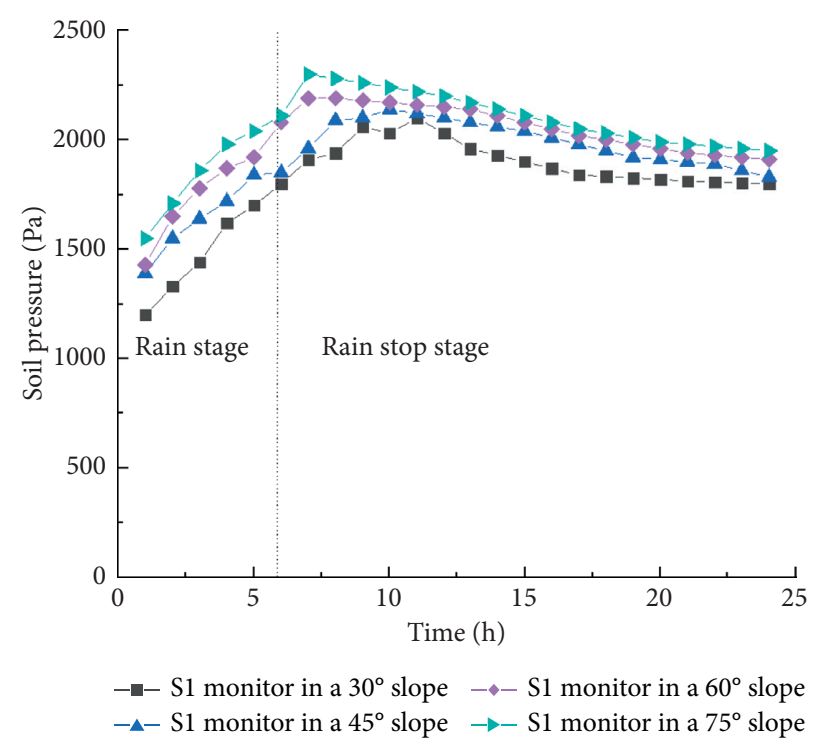

(a)

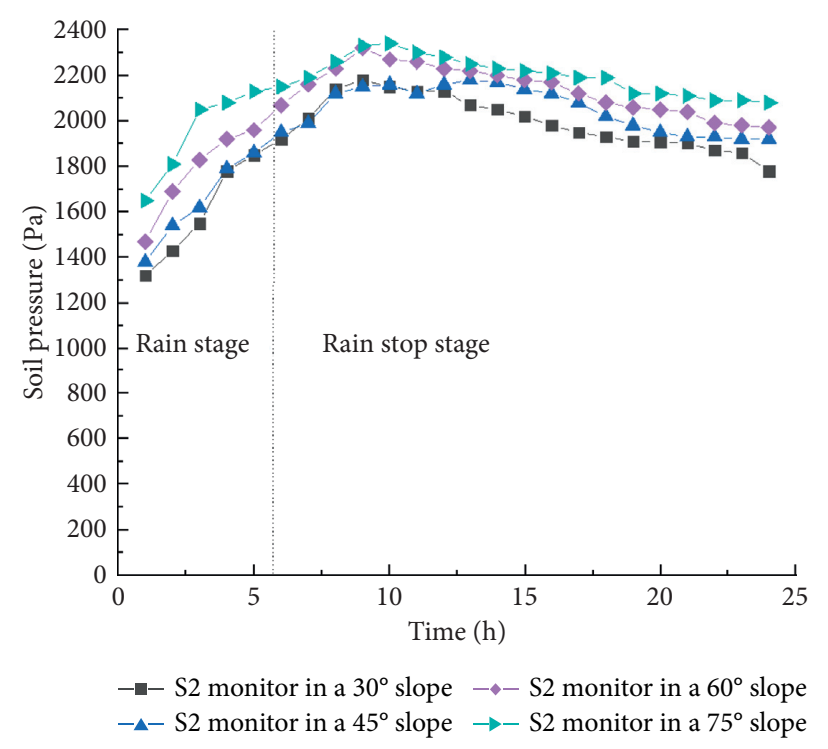

(b)

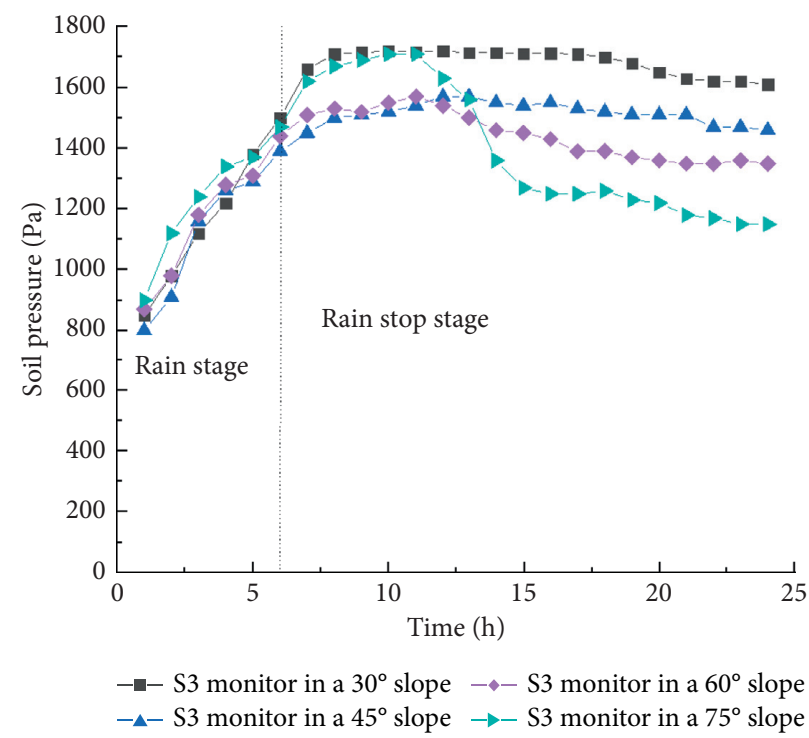

(c)

FIGURE 8: Characteristics of soil pressure on the test models. (a) Soil pressure on the back part of test models by sensor S1. (b) Soil pressure in the middle of the slope by sensor S2. (c) Soil pressure in front of the slope by sensor S3.

These curves indicate that the increase of pore water pressure caused by rainfall infiltration into the weak layer has a "hysteresis" effect. The results from the analysis of the PWP of the test model are listed in Figure 9(b). The lag time of the slope with a $30^{\circ}$ angle is 1 hour, and the lag time of the slope with $60^{\circ}$ is about 4 hours. Such phenomena indicate that the closer to the crack, the faster the pore water pressure dissipates, and the shorter the delay time.

As shown in Figure 9(c), the PWP in the front of the test model also has an increase stage and a decrease stage. From the increase phase of the PWP-time curves, the growth rate is faster than the drop rate in the decline phase of these curves. Meanwhile, these curves also show that the PWP in front of the test model has a lag effect, and the delay time is about 4-7 hours. It indicates that the delay time of the PWP in the back of the test model is larger than that in the front of the slope. Moreover, the PWP will pass through a weak sliding surface (sliding zone) at the front of the slope; then, the water "converges" at the deep deposit in the toe of the slope leading to a rapid rise of the PWP. For example, the PWP is up to $544 \mathrm{~Pa}$ in the closed weak layer on the test model with the $75^{\circ}$ slope angle. It indicates that the water accumulation in the toe of the slope has a negative effect on slope stability, and effective measures such as slope cutting should be taken to reduce the PWP of the closed weak layer at the slope toe.

4.4. Water Content Response Characteristics of Test Model with Different Slope Angles. In order to study the response characteristics of the slope failure with water content after 


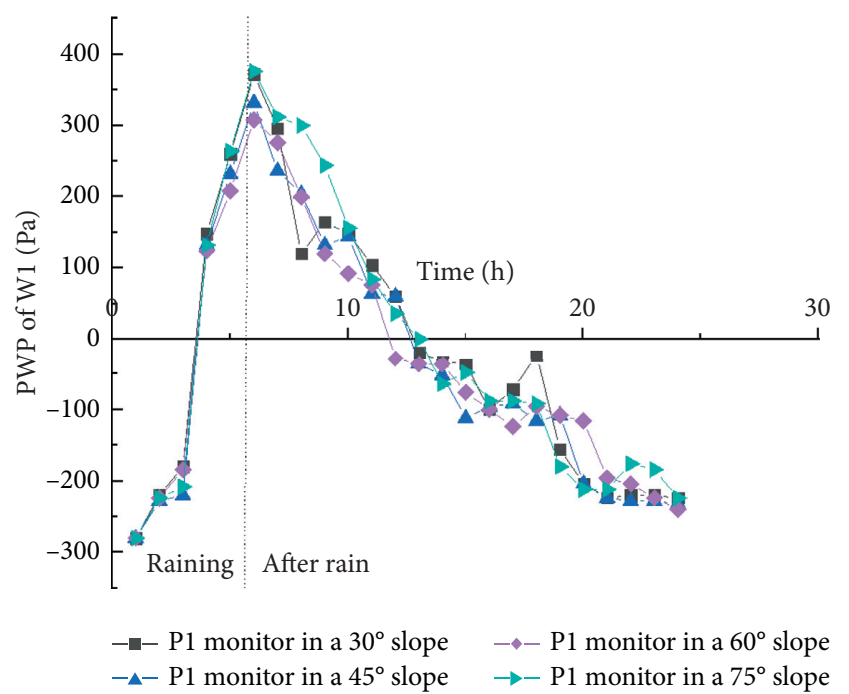

(a)

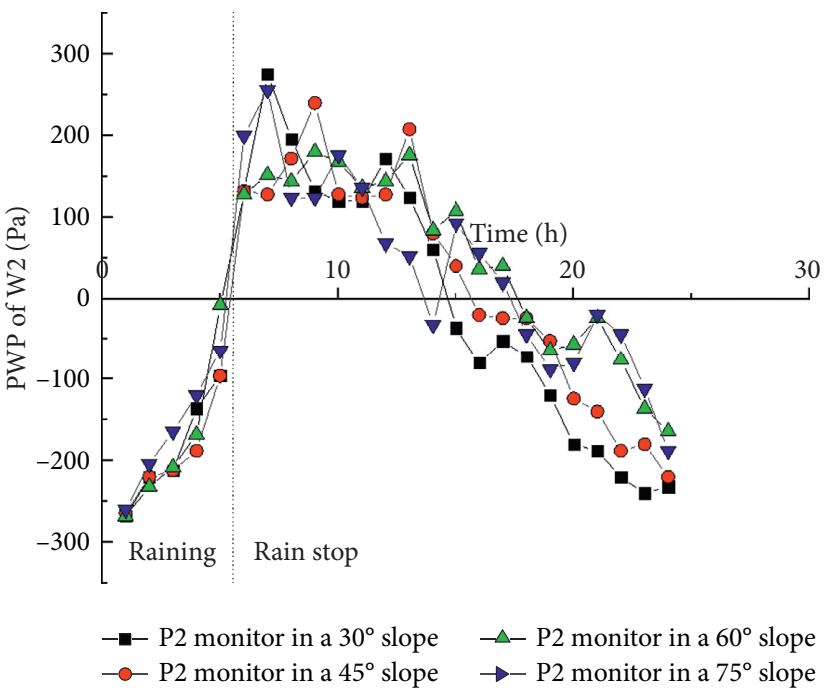

(b)

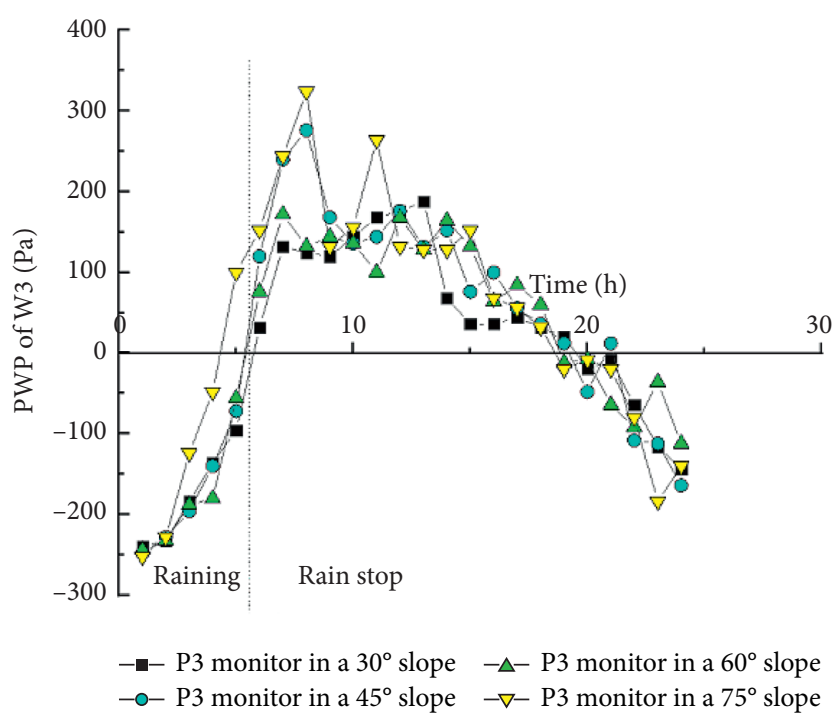

(c)

Figure 9: Characteristics of PWP on the test models. (a) PWP in the back of the test model by sensor P1. (b) PWP in the weak layer by sensor P2. (c) PWP in front of the test model by sensor P3.

the rain, four water content sensors were set at the $240 \mathrm{~mm}$ depth of the test model with different angles. As shown in Figure 10, the water content increases with the rainfall, and the growth rate for the test model with the $30^{\circ}$ slope angle is about $6.8 \% \mathrm{~h}$, the growth rate in the test model with medium grade $\left(45^{\circ}\right)$ is about $11.9 \% \mathrm{~h}$, the growth rate in the steep slope with the $60^{\circ}$ angle is about $7.9 \% \mathrm{~h}$, and steepest slope with $70^{\circ}$ angle is about $4.7 \% \mathrm{~h}$. Each test model was saturated when rainfall is $2.5-6$ hours, and the saturated time sequence is $T_{75^{\circ}}>T_{60^{\circ}}>T_{45^{\circ}}>T_{30^{\circ}}$. The time of soil mass reaching saturation is basically consistent with the order of slope deformation and failure; that is, the shorter the saturation time is, the faster the back part of the slope will form a crack. Moreover, the experiment has shown that the highest saturated water content is $41.9 \%$ in the $30^{\circ}$ slope angle test model followed by $39.6 \%$ in the $45^{\circ}$ angle slope test model,
$37.7 \%$ in the $60^{\circ}$ angle, and $37.5 \%$ in the model with $75^{\circ}$. After the rainfall stopped, the water content of the test model gradually decreased with the diffusion of water. When the rainfall stops, the water contents of the four slopes are similar.

\section{Analysis of the Formation Mechanism of Rainfall-Induced Deposit Landslide}

5.1. Calculation Model and Calculation Process Description. According to the physical model test of soil accumulation landslide, the Geostudio calculation model consistent with the landslide model is established (see Figure 11). The calculation parameters of the landslide model are shown in Table 2. By changing the stress boundary and water head 


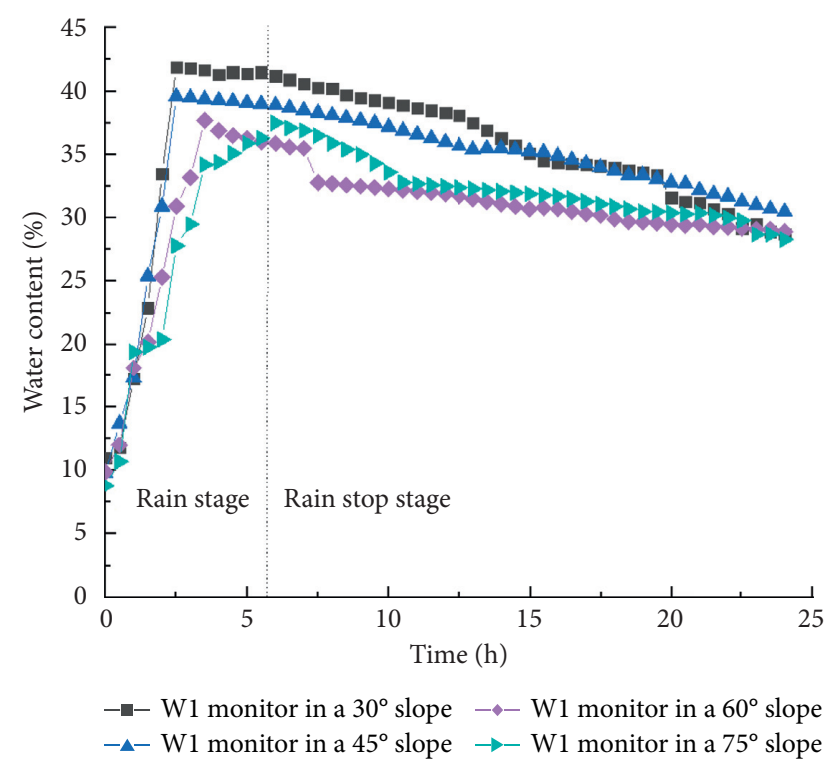

FIGURE 10: Characteristics of water contents in the test model with different angles (W1 sensor location).

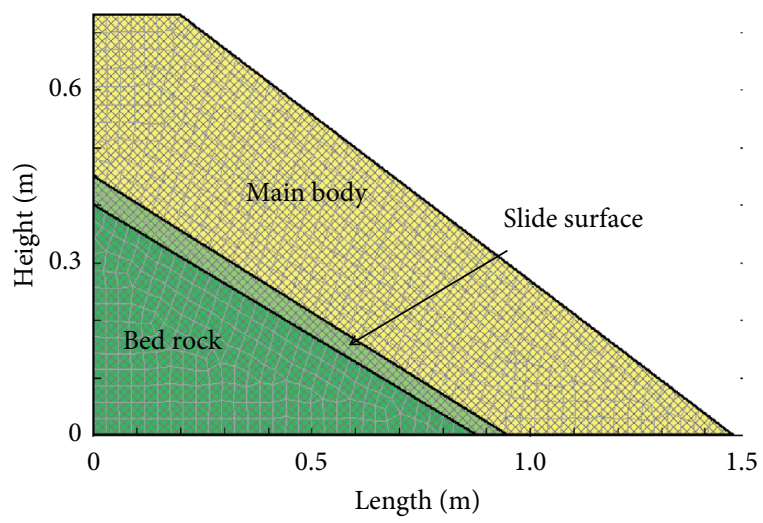

Figure 11: Numerical model of Geostudio.

condition of the shallow layer of the landslide, the evolution process of the landslide model under the condition of graded loading of the landslide body and the change of water level is simulated.

Taking the slope model of 30-degree slope angle accumulation model as an example, the calculation process is as follows:

(1) The model was defined by Geostudio software (Geoslope of the Geostudio $2018 \mathrm{R} 2$ ) and divided into 880 nodes and 821 cells according to the model size. The global cell size was $0.0275 \mathrm{~m}$. According to the elastic solution method, the elastic model is used to calculate the initial in situ stress, and the convergence condition is that the ratio of the unbalanced force to the typical stress is less than $1 \times 10^{-5}$

(2) Under natural conditions, the side and the bottom of the model are set as a fixed boundary, and the $Y$ direction velocity of all points on the boundary of the model is fixed. But in the raining progress, the groundwater level of the model rises, the rainfall function and the head change function are defined, and the soil saturation parameters are taken below the water level. After rainfall, the model's groundwater level drops, the head drop function is defined, and soil saturation parameters are taken below the water level

(3) At the slope surface for the rainfall infiltration boundary, rainfall condition is the same as the physical test; when the rainfall intensity is less than the saturated soil infiltration parameters for flow infiltration boundary, the soil is greater than the saturation coefficient for head boundary; the VanGenuchen fitting equation was used in the Geostudio with a change in the parameters of layers to study the change of stress and strain

5.2. Result Analysis. The slope with an angle of $30^{\circ}$ is still taken as an example, and the stress and strain of the slope simulated by the limit equilibrium Morgenstern-Price method are shown in Figures 10 and 11, respectively.

Figure 12(a) is the total stress field of the slope under the initial natural condition, while Figure 12(b) is the total strain field under the natural condition. As can be seen from the figure, the maximum stress generated by the total stress of the model under natural working conditions is located at the limestone base of $1.6 \mathrm{kPa}$. Stress concentration is generated at the top and bottom of the weak sandwich, and the stress concentration at the top is $1.2 \mathrm{kPa}$ which is greater than $0.8 \mathrm{kPa}$ at the bottom. At the top and bottom of the model slope, a large strain appeared, which is up to 0.001 . It is shown that, under natural conditions, the model generates a stress concentration concentrated in the weak interlayer, and a small deformation was produced in the slope foot.

Figure 13(a) shows the total stress field after 6 hours of rainfall, while Figure 13(b) shows the total strain field after 6 hours of rainfall. It can be seen from the diagram that after 6 hours of the rain, there is a rise in the ground water level to $0.09 \mathrm{~m}$. The positive pore water pressure in the slope is produced firstly, the negative pore-water pressure to complete disappears, then a new stress concentration phenomenon is present in the slide surface, and the stress concentration phenomenon occurs mainly in the trailing edge slope of weak intercalations. The displacement values of slope sliding zone trailing edge and leading edge are increased. This shows that the weak interlayer has a great influence on the landslide.

Figure 14(a) shows the seepage water pressure field of a landslide after 10 hours of rainfall, and Figure 14(b) shows the maximum principal strain field after 10 hours of rainfall. As can be seen from the figure, after 10 hours of rainfall, PWP is increased significantly, stress concentration occurred at the foot of the slope, and the maximum principal stress reached $1.6 \mathrm{kPa}$. The displacement concentration area at the bottom of the weak interlayer moves to the toe of the slope, indicating that rainfall has a great influence on the pore water pressure along the weak interlayer. When the slope with an angle of $30^{\circ}$ is influenced by the 10-hour 


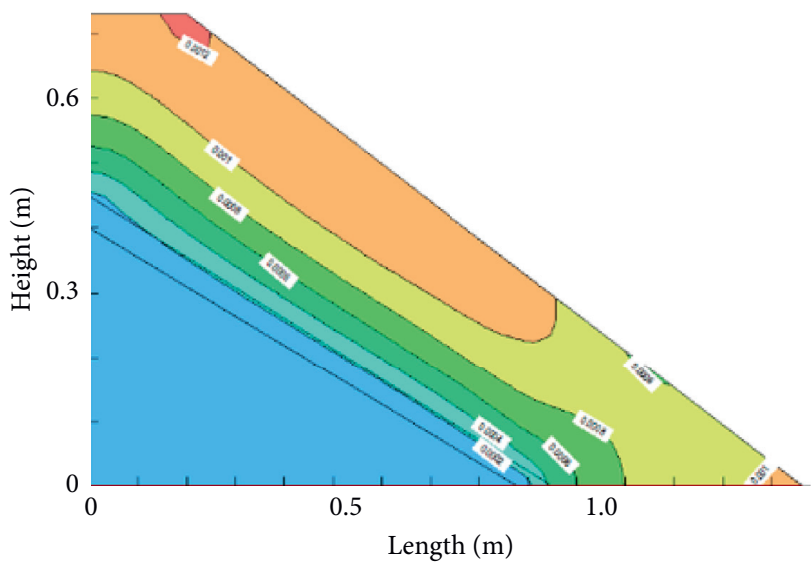

(a)

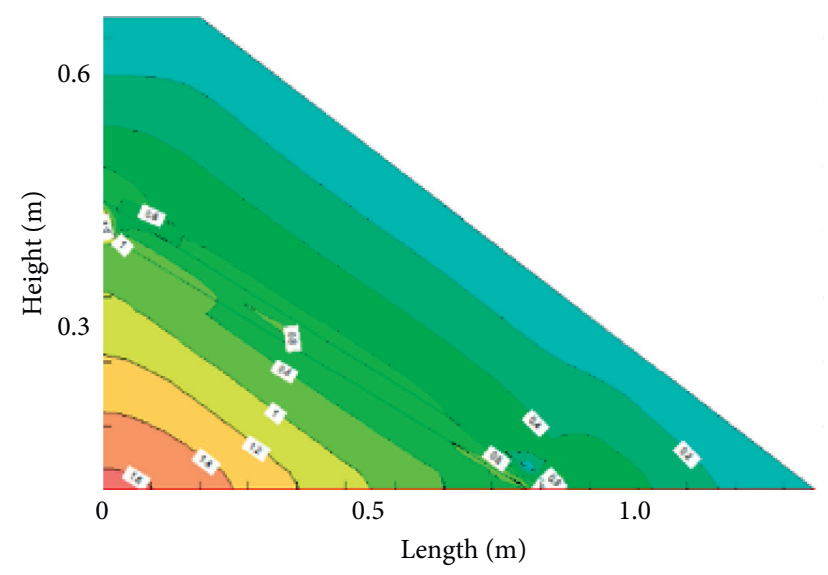

(b)

Figure 12: Initial values of total stress and total strain of landslide. (a) Initial value of total stress $(t=0 \mathrm{~h}$ ). (b) Initial value of total strain $(t=0 \mathrm{~h})$.

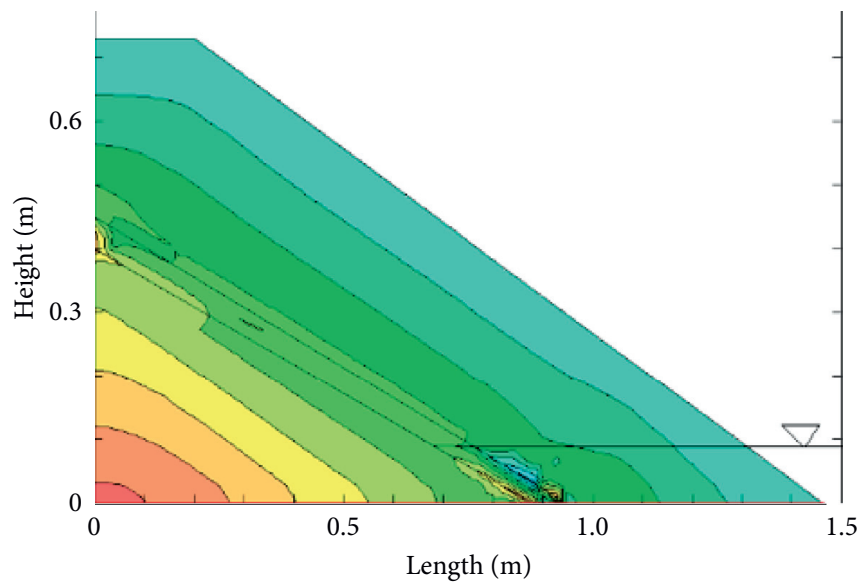

(a)

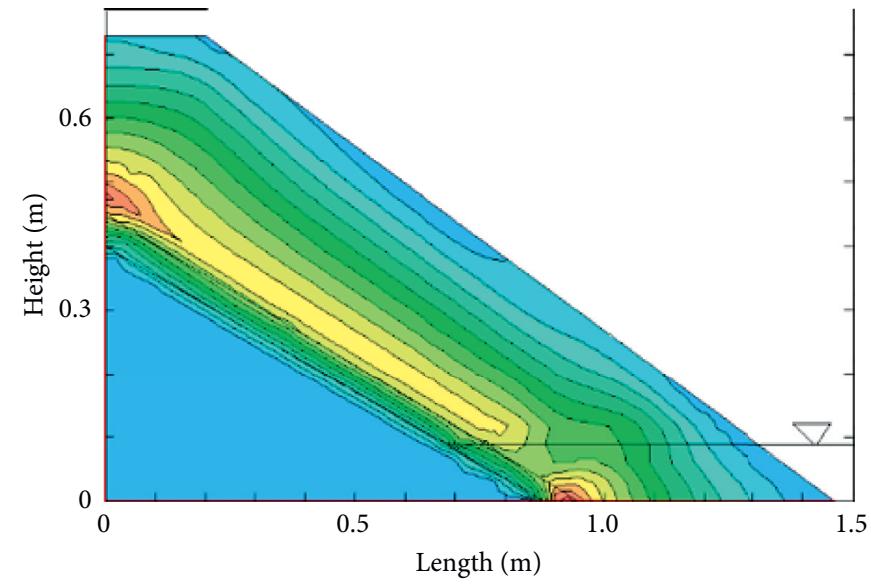

(b)

Figure 13: The total strain and stress after 6 hours of the accumulation landslide. (a) Total stress of landslide $(t=6 \mathrm{~h})$. (b) Total strain of landslide $(t=6 \mathrm{~h})$.

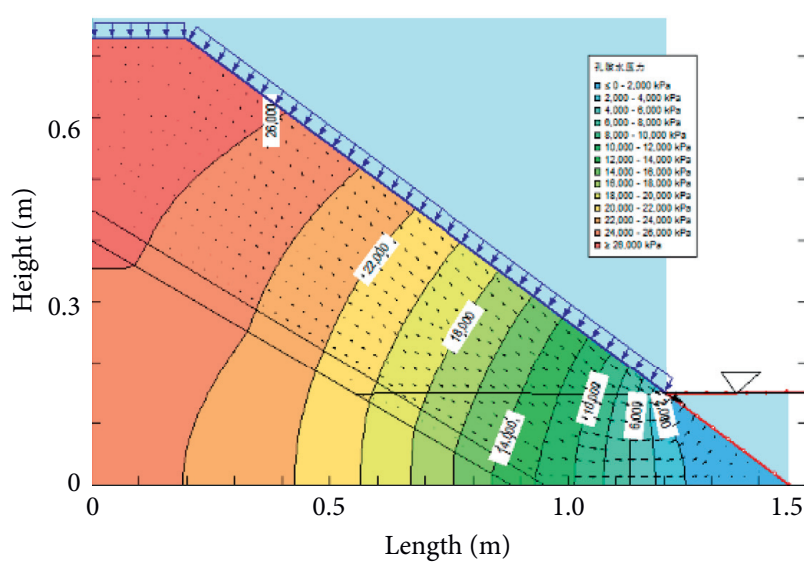

(a)

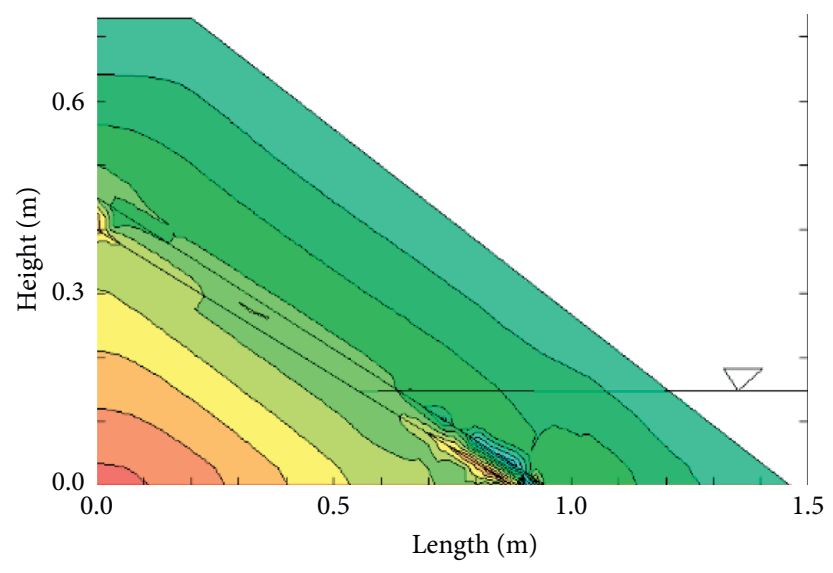

(b)

Figure 14: PWP and maximum principal stress of landslide 10 hours after rainfall. (a) PWP of the model ( $t=10 \mathrm{~h})$. (b) Maximum strain of the model $(t=10 \mathrm{~h})$. 
rainfall, the maximum principal stress is mainly concentrated in the leading edge of slope toe, which is similar to the results of physical simulation. The maximum principal strain extends in the weak interlayer and forms a slide zone, which leads to the landslide.

By comparing the relationship between the time step and the changes of stress and strain, the landslide model is obviously correlated with the soft interlayer and slope angle in the process of rainfall, which verifies the characteristics of tensile crack at the back edge of the bedding gentle slope, extrusion at the front edge, and bedded deformation, as well as the characteristics of collapse at the front edge of the steep slope, descending at the back edge, and traction deformation and failure.

\section{Conclusion}

According to the model test and numerical analysis, it is concluded that two stages of displacement and three failure stages exist in deposit landslide with a weak layer with each having a special characteristic. Under the condition of the same rainfall, the displacement and soil pressure change in the trailing edge at $30^{\circ}$ or $45^{\circ}$ slope is greater than displacement and soil pressure in the front of the slope, and it has the characteristics of creep and retrogressive.

However, the displacement in the front of the test model with a $60^{\circ}$ or $75^{\circ}$ slope angle is greater than the displacement in the back of the slope, and it is prone to occur suddenly leading to traction landslide. In general, the rainfall infiltration causes weak intercalations, and PWP rises in a short time during the rain but still maintains a certain degree of growth after rainfall stops. It has some delay in time and a negative correlation with slope angles. In the weak layer, the PWP rises and dissipates for a longer time lag. Rainfall leads to the accumulation of PWP in the weak layer after the rainfall stops so that the sliding body maintains a long period of inertial creep. The gentler the slope is, the shorter the soil saturation time is and the faster the slope failure occurs. The deformation characteristics are generally characterized by the trailing edge crack and the front of the slope bulge, and the slope deformation and failure are generally divided into three stages: creep inoculation, accumulation uplift, and speed-up sliding.

Moreover, this test model can study complicated slope failure and deformation and can determine the factor of safety for the slope with a weak layer. From these tests, the weak layer should be paying more attention, the drainage system should be set at the back of slope to prevent surface water from infiltrating along the crack, and water guiding measures should be taken in the front of the slope to prevent the concentration of groundwater in the weak layer which can cause a sudden instability [23].

\section{Data Availability}

The data used to support the findings of this study are included within the article.

\section{Conflicts of Interest}

The authors declare that there are no conflicts of interest regarding the publication of this paper.

\section{Acknowledgments}

This research was partially supported by the National Science Foundation of China (NSFC) (Nos. 41641023 and 51869012), the Natural Science Foundation of Jiangxi Province (No. 20171BAB213027), and Jiangxi Provincial Key Scientific Research Plan (No. 20177BBG70046). The authors thank Prof. Huang Runqiu and Prof. Pei XiangJun at the Chengdu University of Technology, whose reviews helped improve this manuscript. They would also like to thank the Soil and Water Conservation Ecological Science Park of Jiangxi Provincial for providing them with a good rainfall system and service support.

\section{References}

[1] R. Q. Huang, "Large-scale landslides and their sliding mechanisms in China since the 20th century," Chinese Journal of Rock Mechanics and Engineering, vol. 26, no. 3, pp. 04330455, 2007.

[2] R. W. Jibson, "The 2005 La Conchita, California, landslide," Landslide, vol. 3, no. 1, pp. 73-78, 2006.

[3] R. W. Jibson, "Landslide hazards at La conchita, California," USGS Open File Report 2005-1067, pp. 12-32, USGS, Reston, VA, USA, 2005.

[4] R. Q. Huang and X. M. Fan, "The landslide story," Nature Geoscience, vol. 6, no. 2, pp. 325-326, 2013.

[5] J. J. Gan, J. H. Fan, and C. Tan, "Sucun landslide in suichang county of zejiang province: charcteristices and failure mechanism," Journal of Catastrophology, vol. 32, no. 4, pp. 73-78, 2017.

[6] C. Ouyang, W. Zhao, Q. Xu et al., "Failure mechanisms and characteristics of the 2016 catastrophic rockslide at Su village, Lishui, China," Landslides, vol. 15, no. 7, pp. 1391-1400, 2018.

[7] H. K. Chen and H. M. Tang, "Research on strat-up of loose landslide in lab," Journal of Mountain Science, vol. 30, no. 1, pp. 112-115, 2002.

[8] G. Forte, M. Pirone, A. Santo, M. V. Nicotera, and G. Urciuoli, "Triggering and predisposing factors for flow-like landslides in pyroclastic soils: the case study of the Lattari Mts. (southern Italy)," Enigneering Geology, vol. 257, 2019.

[9] G. B. Crosta and P. Frattini, "Distributed modelling of shallow landslides triggered by intense rainfall," Natural Hazards and Earth System Sciences, vol. 3, no. 3, pp. 81-93, 2003.

[10] D. Li, Y. M. Li, and M. Zhang, "Analysis of original deformation for sliding zone of talus slide," Chinese Journal of Rock Mechanics and Engineering, vol. 25, no. S2, pp. 3879-3884, 2006.

[11] Z. Zhou, H. L. Fu, B. C. Liu, H.-H. Tan, and W.-X. Long, "Artificial rainfall test on a well-instrumented soil-rockmixture slope," Rock and Soil Mechanics, vol. 28, no. 7, pp. 1391-1397, 2007.

[12] S. Maghous, Z. Saada, L. Dormieux, J. Canou, and J. C. Dupla, "A model for in situ grouting with account for particle filtration," Computers and Geotechnics, vol. 34, no. 3, pp. 164174, 2007.

[13] Y. C. Ye, Y. W. Shi, and Q. H. Wang, "Test model research on low strength similar material of Shanghengshan multilayer shale deposit," Rock and Soil Mechanics, vol. 35, no. 2, pp. 114-120, 2014.

[14] L. T. Gao, E. C. Yan, and L. Ke, "Accumulation landslides under rainfall condition-a case from Chongqing," Journal of Engineering Geology, vol. 22, no. 2, pp. 263-272, 2014. 
[15] D. J. Wang, H. M. Tang, and C. D. Li, "Stability analysis of colluvial landslide due to heavy rainfall," Rock and Soil Mechanics, vol. 37, no. 2, pp. 439-446, 2016.

[16] H. Tian, L. W. Kong, and B. Li, "Centrifugal modeling tests on stability of deposits slope under rainfall," Rock and Soil Mechanics, vol. 36, no. 11, pp. 3180-3187, 2015.

[17] S. Jeong, K. Lee, J. Kim, and Y. M. Kim, "Analysis of rainfallinduced landslide on unsaturated soil slopes," Sustainability, vol. 9, no. 7, pp. 1-20, 2017.

[18] P. Sun, G. Wang, L. Z. Wu, O. Igwe, and E. Zhu, "Physical model experiment for shallow failure in rainfall-triggered loess slope, northwest China," Bulletin of Engineering Geology and the Evironment, vol. 78, no. 6, pp. 1420-1425, 2019.

[19] M. R. Yeung, Q. H. Jiang, and N. Sun, “A model of edge-toedge contact for three-dimensional discontinuous deformation analysis," Computers and Geotechnics, vol. 34, no. 3, pp. 174-186, 2007.

[20] X. Q. Luo and J. F. Bi, Geomechanics Model Test Theory and Applicaiton, pp. 56-78, Shanghai Jiaotong University Press, Shanghai, China, 2016.

[21] M. Zaman, G. Gioda, and J. R. Booker, Modeling in Geomechanics, pp. 121-132, Wiley, New York, NY, USA, 2000.

[22] L. Z. Wu, R. Q. Huang, Q. Xu, L. M. Zhang, and H. L. Li, "Analysis of physical testing of rainfall-induced soil slope failures," Environmental Earth Sciences, vol. 73, no. 12, pp. 8519-8531, 2015.

[23] H. Fang, P. Cui, L. Z. Pei, and X. J. Zhou, "Model testing on rainfall-induced landslide of loose soil in Wenchuan earthquake region," Natural Hazards and Earth System Sciences, vol. 12, no. 3, pp. 527-533, 2012.

[24] Ž. Ortolan and J. Pleško, "Repeated photogrammetric measurements at shaping geotechnical models of multi-layer landslides," Rudarsko Geološko Naftni Zbornik, vol. 4, pp. 51-58, 1992.

[25] Z. He and B. Wang, "Instability process model test for bedding rock slope with weak interlayer under different rainfall conditions," Advances in Civil Engineering, vol. 2018, Article ID 8201031, 8 pages, 2018. 